\title{
Beneficial effect of feeding olive pulp and Aspergillus awamori on productive performance, egg quality, serum/yolk cholesterol and oxidative status in laying Japanese quails
}

\author{
A.E. Abd El-Moneim ${ }^{1}$ and E.M. Sabic \\ Atomic Energy Authority, Nuclear Research Center, Biological Application Department, \\ Abou-Zabael 13759, Egypt
}

KEY WORDS: olive pulp, Aspergillus awamori, egg quality, cholesterol, oxidative status, quails $\begin{array}{lr}\text { Received: } & 18 \text { June } 2018 \\ \text { Revised: } & 16 \text { November } 2018 \\ \text { Accepted: } & 15 \text { March } 2019\end{array}$

${ }^{1}$ Corresponding author:

e-mail: aeabdelmoneim@gmail.com

\begin{abstract}
In the twelve-week study, the effect of feeding olive pulp (OP) without or with Aspergillus awamori on performance, egg quality, serum lipids and antioxidant status of 360 8-week-old laying Japanese quail hens was evaluated. Birds were randomly distributed to 6 groups: control $(C)$ receiving maize-soybean basal diet with no additives, the other supplemented with: $0.1 \%$ A. awamori (A) containing $3 \times 10^{6} A$. awamori spores $/ g, 5 \% \mathrm{OP}\left(\mathrm{OP}_{5}\right), 5 \%$ $\mathrm{OP}+0.1 \%$ A awamori $\left(\mathrm{OP}_{5} \mathrm{~A}\right), 10 \% \mathrm{OP}\left(\mathrm{OP}_{10}\right)$ or $10 \% \mathrm{OP}+0.1 \%$ A awamori $\left(\mathrm{OP}_{10} \mathrm{~A}\right)$. It was shown that egg weight and number were increased $(P<0.05)$ in groups fed OP with or without $A$. awamori in comparison to $C$ group, while final body weight, feed consumption, feed conversion ratio and egg mass did not differ between treatments. Yolk (\%) and yolk:albumin ratio were enhanced $(P<0.05)$ in groups $\mathrm{OP}_{5} \mathrm{~A}, \mathrm{OP}_{10}$ and $\mathrm{OP}_{10} \mathrm{~A}$, while egg shape index was improved in all treatment groups except $\mathrm{OP}_{10}$ group during the last experimental period (16-20 week of age). The hypocholesterolemic effect of OP and A. awamori was greatly noticed, where yolk contents of cholesterol and total lipids and serum levels of triglycerides, cholesterol and LDL cholesterol were reduced in nearly all treated groups. Antioxidant status of birds from supplemented groups was improved $(P<0.01)$ as reduced glutathione content and glutathione reductase activity were increased, while lipid peroxidation was decreased. So, dietary supplementation of OP with or without $A$. awamori can improve performance, egg cholesterol content, serum lipid profile and antioxidant status of laying Japanese quail hens during early laying periods.
\end{abstract}

\section{Introduction}

Poultry industry faces realistic challenge and ever-increasing problem of incessant rising in prices and limited amounts of high-quality feed materials. Thus, the feed costs can be reduced by using low-cost and locally available feedstuffs. So, it is required to constantly evaluate new feed sources, including agri- culture by-products and food-industry wastes. Olive pulp (Olea europaea L., OP) represents one of the residues used as partially alternative to feed ingredients. OP is the remaining raw material from the olive oil extraction (mechanical or solvent method) after the removal of the seed fractions. Depending on oil extraction method, crude fat content can vary in the pulps. Indeed, the OP may be partly considered as 
an energy source in poultry feed. It is a good source of $\alpha$-linolenic acid with high free radicals scavenging activity because of its phenolic components (e.g., oleuropein and hydroxytyrosol) (Hashish and Abd El-Samee, 2005; Güçlü et al., 2008; Bulotta et al., 2014). Nevertheless, the relative high content of crude fibre in OP limits its use in poultry diets; so, further treatments (mechanical, chemical or biological) are required.

Aspergillus awamori, a variant of Aspergillus niger, has been used for the processing of Japanese distilled liquor (Shochu) called 'koji'. The products processed by or containing A. awamori have been recognized as safe by the USA Food and Drug Administration (Saleh et al., 2017). It is very provable that $A$. awamori had a superior ability to secrete enzymes (e.g., $\alpha$-amylases, glucoamylases and proteases) enhancing digestions of carbohydrates and proteins, and produce a growth promoter during the fermentation as well as its role as probiotic (Panda et al., 2006; Saleh et al., 2017).

The aim of the present study was to evaluate the effect of feeding quails diets supplemented with OP with or without $A$. awamori addition. OP effect can be connected with the beneficial antioxidant components found in it. The possible mechanisms by which A. awamori exerts effect are: its superior ability to secrete enzymes able to degrade the non-starch polysaccharides (NSP) and fibre contents of OP, and its role as a probiotic. In addition, the ability to lower egg cholesterol levels had been previously reported for both OP (Hashish and Abd El-Samee, 2005; Saleh et al., 2017) and A. awamori (Imaizumi et al., 1992; Hara et al., 1999; Tang et al., 2015), and this coincides with the increasing demand for low-cholesterol or unsaturated fatty acids in eggs. Therefore, in this study, laying quails were selected as experimental subject to examine the effect of $\mathrm{OP}$ with or without $A$. awamori dietary inclusion on their productive performance, egg quality, and biochemical and antioxidant status.

\section{Material and methods}

The experiment was carried out at the experimental poultry farm of the Poultry Research Unit, Biological Application Department, Radioisotopes Applications Division, Nuclear Research Center, Egyptian Atomic Energy Authority at Inshas (Egypt). All procedures were approved by Local Experimental Animals Care Committee and Institutional Ethics Committee. The birds were cared using husbandry guidelines derived from Egyptian Atomic Energy Authority standard operating procedures.

\section{Animals and diets}

In total, 360 8-week-old laying Japanese quail hens with nearly the same body weight were randomly divided into six groups. Each group had three replicates (20 quails each) which were caged in wire battery cages $(100 \times 60 \times 50 \mathrm{~cm}$; length $\times$ width $\times$ height) under the same managerial, hygienic and environmental conditions. The experiment was conducted in autumn season and ambient temperature ranged from $20-25{ }^{\circ} \mathrm{C}$. Cages were equipped with stainless steel nipple drinker. Feed in mash form and water were available ad libitum for each cage throughout the whole study. The light cycle was $16 \mathrm{~h}$ during the experiment period (three months) from October to December. The trial started at 8 week of age, and lasted for 12 weeks ( 20 week of age). The control group (C) received a maize-soybean basal diet with no additives. The basal diet was formulated to meet the bird dietary nutrient requirements (NRC, 1994). The other treatment groups were fed the basal diet supplemented with: $1 \mathrm{~g}$ Tomoko $/ \mathrm{kg}$ (A), $5 \%$ olive pulp $\left(\mathrm{OP}_{5}\right), 5 \%$ olive pulp $+1 \mathrm{~g}$ Tomoko/ $\mathrm{kg}\left(\mathrm{OP}_{5} \mathrm{~A}\right), 10 \%$ olive pulp $\left(\mathrm{OP}_{10}\right)$ or $10 \%$ olive pulp $+1 \mathrm{~g}$ Tomoko $/ \mathrm{kg}\left(\mathrm{OP}_{10} \mathrm{~A}\right)$. Tomoko is the product of Biogenkoji Research Institute (Kagoshima, Japan), which contains $3 \times 10^{6} \mathrm{~A}$. awamori spores per g. The composition and the calculated analysis of the experimental diets are shown in Table 1.

\section{Nutrients and fatty acid composition of olive pulp}

De-stoned, dried and grounded olive pulp was analysed for chemical composition (Table 1). Dry matter (DM) (2000 \#930.15), crude protein (CP) (2000 \#984.13), crude fibre (CF) (2000 \#973.18), ether extract (EE) (2003 \#2003.05) and ash (2000 \#923.03) contents in OP were analysed according to the AOAC International procedures (AOAC International, 2000, 2003). The following formula was used to calculate nitrogen free extract (NFE) according to Scott et al. (1976):

$$
\mathrm{NFE}=\mathrm{DM} \%-(\mathrm{CP} \%+\mathrm{EE} \%+\mathrm{CF} \%+\mathrm{Ash} \%)
$$

Fatty acids were determined by gas chromatography coupled with mass spectrometry (GC-MS) (Thermo Fisher, Waltham, MA, USA) after its conversion to fatty acid methyl esters according to Saleh et al. (2012). Relative composition of fatty acids was calculated as the $\%$ of the total fatty acids (Table 2 ).

\section{Data collection and egg parameters}

Body weight was recorded at the beginning and at the end of the experiment, while feed consump- 
Table 1. Composition and calculated analysis of experimental diets, and the proximate composition of the olive pulp

\begin{tabular}{|c|c|c|c|}
\hline \multirow{2}{*}{ Indices } & \multicolumn{3}{|c|}{ Olive pulp concentrations } \\
\hline & control $(0 \%)$ & $5 \%$ & $10 \%$ \\
\hline \multicolumn{4}{|l|}{ Ingredients, \% } \\
\hline yellow maize & 53.9 & 47.6 & 40.6 \\
\hline soybean meal (44\%) & 34.5 & 34.5 & 34.9 \\
\hline dicalcium phosphate & 1.20 & 1.10 & 1.10 \\
\hline limestone & 5.70 & 5.70 & 5.70 \\
\hline sodium chloride & 0.30 & 0.30 & 0.30 \\
\hline vitamin-mineralpremix ${ }^{1}$ & 0.30 & 0.30 & 0.30 \\
\hline dl-methionine & 0.15 & 0.15 & 0.15 \\
\hline soybean oil & 4.00 & 5.35 & 7.00 \\
\hline olive pulp & 0.00 & 5.00 & 10.0 \\
\hline \multicolumn{4}{|l|}{ Calculated values ${ }^{2}, \%$} \\
\hline crude protein & 20.07 & 20.02 & 20.06 \\
\hline metabolizable energy (ME) MJ/k & 12.20 & 12.15 & 12.15 \\
\hline crude fibre & 3.60 & 4.46 & 5.73 \\
\hline lysine & 1.14 & 1.13 & 1.12 \\
\hline methionine & 0.48 & 0.47 & 0.46 \\
\hline methionine + cysteine & 0.80 & 0.78 & 0.76 \\
\hline calcium & 2.51 & 2.51 & 2.53 \\
\hline available phosphorus & 0.36 & 0.35 & 0.35 \\
\hline \multicolumn{4}{|c|}{ Proximate composition of the olive pulp, analyzed } \\
\hline dry matter (DM), \% & & 87.2 & \\
\hline crude protein, g/kg DM & & 97 & \\
\hline crude fibre, g/kg DM & & 200 & \\
\hline nitrogen free extract, g/kg DM & & 378 & \\
\hline crude fat, g/kg DM & & 107 & \\
\hline ash, g/kg DM & & 80 & \\
\hline
\end{tabular}

${ }^{1}$ vitamin-mineral premix provided per kg diet: IU: vit. A 4000000 , vit. $D_{3} 500000$; g: vit. $E 16.7$, vit. $K 0.67$, vit. $B_{1} 0.67$, vit. $B_{2} 2$, vit. $B_{6} 67$, vit. $B_{12} 0.004$, nicotinic acid 16.7 , pantothenic acid 6.67, biotin 0.07 , folic acid 1.67, choline chloride $400, \mathrm{Zn} 23.3$, Mn 10, Fe 25, Cu 1.67, I 0.25, Se 0.033, Mg 133.4; ${ }^{2}$ calculated according to National Research Council (NRC, 1994)

tion (FC) was recorded weekly. Feed conversion ratio (FCR) was calculated as: g feed/g egg. Egg number $(\mathrm{EN})$ and egg weight $(\mathrm{EW})$ were monitored daily to calculate the egg mass $(\mathrm{EM}=\mathrm{EN} \times \mathrm{EW})$.

\section{Egg quality criteria}

Egg and eggshell quality examinations (eggshell thickness, shell, yolk and albumen weights (\%), yolk index, yolk:albumen ratio, egg shape index and Haugh Unite (HU) score were conducted using an average of 10 eggs laid between 12:00 and 15:00 from each treatment replicate which were randomly collected at the ends of 12,16 , and 20 week of age. After eggs weighing and measuring their length and width, the eggs were carefully broken on a glass plate $(35 \times 35 \mathrm{~cm})$ to measure external and internal egg quality criteria. Yolks were isolated from albumen
Table 2. Fatty acid composition of olive pulp ${ }^{1}$

\begin{tabular}{lc}
\hline Indices & Olive pulp \\
\hline Saturated fatty acids (SFAs), $\%$ & \\
$\quad$ C16:0 (palmitic) & $14.24 \pm 1.12$ \\
C18:0 (stearic) & $2.51 \pm 0.19$ \\
C20:0 (arachidonic) & $0.46 \pm 0.07$ \\
$\quad$ ¿SFAs & 17.21 \\
Monounsaturated fatty acids (MUFAs), \% & \\
$\quad$ C16:1 (palmitoleic) & $1.51 \pm 0.08$ \\
C18:1 (oleic) & $68.02 \pm 5.76$ \\
C20:1 (eicosenoic) & $0.25 \pm 0.02$ \\
$\quad$ IMUFAs & 69.78 \\
Polyunsaturated fatty acids (PUFAs), \% & \\
$\quad$ C18:2 (linoleic) & $12.18 \pm 0.92$ \\
C18:3 (a-linolenic) & $0.83 \pm 0.09$ \\
$\quad$ IPUFAs & 13.01 \\
PUFAs/SFAs & 0.756 \\
MUFAs/PUFAs & 5.364 \\
\hline${ }^{1}$ values are presented as means \pm SEM ( $\mathrm{n}=5$ )
\end{tabular}

${ }^{1}$ values are presented as means \pm SEM $(n=5)$

and weighed. To measure shell weight, eggshells were cleaned of any clinging albumen; eggshells were then dried at room temperature and weighed. Albumen weight was ascertained by subtracting the weights of yolk and shell from the whole egg weight. Yolk, albumen and shell weights were expressed as a percentage of the whole egg. Shell thickness (with shell membrane) was determined from mean estimations of shell thickness at three areas on the egg (air cell, equator and sharp end) using a micrometer. Yolk diameter was measured to the nearest $0.05 \mathrm{~mm}$ by a vernier caliper, however yolk height was measured to the nearest $0.01 \mathrm{~mm}$ by means of tripod micrometer reading. The yolk index was calculated as the yolk height divided by yolk diameter while egg shape index was calculated as the ratio of egg width to length. HU score was computed according the following equation:

$$
\mathrm{HU}(\%)=100 \times \log \left(\mathrm{H}+7.57-1.7 \times \mathrm{W}^{0.37}\right)
$$

where: $\mathrm{H}$ and $\mathrm{W}$ refer to albumen height and egg weight, respectively. Yolk total lipids and cholesterol were determined by 10 eggs from each treatment and measured by the methods of Folch et al. (1957) and Washburn and Nix (1974).

\section{Blood sampling and biochemical analysis}

At the end of the experimental period, six quails from each group were randomly chosen and blood samples were collected from the brachial vein in tube without anticoagulant for separate serum; then the samples were immediately centrifuged at $4500 \mathrm{rpm}$ for 15 min and the obtained serum was stored at $-20^{\circ} \mathrm{C}$ 
until further analysis. The total protein, albumin, total cholesterol (TC), triglycerides (TG), low-density lipoprotein (LDL) cholesterol and high-density lipoprotein (HDL) cholesterol serum concentrations and aspartate aminotransferase (AST), alanine aminotransferase (ALT) and alkaline phosphatase (ALP) serum activities were analysed using spectrophotometer (Spectronic 1201, Milton Roy, Ivyland, PA, USA) using commercial kits (Spinreact Co., Girona, Spain) according to the manufacturer's instructions. The reduced glutathione (GSH) and malondialdehyde (MDA) contents, and glutathione reductase (GSR) activity in the serum were analysed using commercial kits (Cell Biolabs Inc., San Diego, CA, USA).

\section{Statistical analysis}

Data were analysed by two-way analysis of variance (ANOVA) using the General Linear Models (GLM) procedure of the statistical software SPSS (ver. 18.0; IBM Corp., Armonk, NY, USA). Tukey's multiple comparison tests were used to identify which treatment conditions were significantly different from each other at a significance level of $P<0.05$.

\section{Results and discussion}

\section{Productive performance}

There were no significant differences in initial and final body weights, daily FC, FCR and EM of quails among experimental treatments (Table 3). However, EW was increased in $\mathrm{OP}_{5} \mathrm{~A}$ and $\mathrm{OP}_{10}$ groups during the periods from 16-20 week of age and only in $\mathrm{OP}_{5} \mathrm{~A}$ in the overall one. The EN was increased in all groups receiving OP regardless A. awamori addition in periods $12-16,16-20$ week of age and the overall period, meanwhile there was no difference between groups $\mathrm{A}$ and $\mathrm{C}$. The highest values of $\mathrm{EW}$ and $\mathrm{EN}$ were recorded in $\mathrm{OP}_{5} \mathrm{~A}$ and $\mathrm{OP}_{10}$ groups followed by $\mathrm{OP}_{5}$, mainly in overall period. There were no mortality in all treatment groups. These increment in EW and EN may be due to the residues of olive oil and its high contents of polyunsaturated fatty acids, mainly $\alpha$-linoleic acid (March and MacMillan, 1990; Grobas et al., 1999, 2001; Güçlü et al., 2008). In addition, the eminent ability of $A$. awamori to produce cellulase and xylanase, and digest raw starches as well as soluble NSP (Saleh et al., 2017) found in the diet and OP, besides its role as probiotic, may enhance the utilization of OP and diet ingredients which in result improves quail productive performance. The previous aspects may be considered as explanations of the enhance- ment effect observed in the aforementioned groups. Our results are in agreement with recent reports investigating the productive performance. Many studies observed the insignificant effect of OP inclusion up to $10 \%$ into laying hen diets on productive performance except EW (Zangeneh and Torki, 2011; Zarei et al., 2011; Al-Harthi and Attia, 2015). Moreover, the dietary addition of $A$. awamori increased EW and egg mass with no noticeable effect on the average body weight gain of hens (Saleh et al., 2017). Egg production in hens fed diets with probiotic content of bacteria and fungi was not significantly affected in hens aged from 40 to 52 week (Ramasamy et al., 2009), but it was significantly higher during the late laying period, from 54 to 65 week of age (Yörük et al., 2004).

\section{Egg quality criteria}

All examined egg quality parameters were insignificantly affected by supplemented OP and A. awamori either separated or combined during the experimental periods from 8-12 and 12-16 week of age (Table 4). However, during the last experimental period (16-20 week of age) yolk (\%) and yolk:albumen ratio increased significantly in groups $\mathrm{OP}_{10}, \mathrm{OP}_{5} \mathrm{~A}$ and $\mathrm{OP}_{10} \mathrm{~A}$ in comparison to $\mathrm{C}$ group. Furthermore, egg shape index was elevated significantly in all treatment groups except $\mathrm{OP}_{10}$, while HU score was increased only in $\mathrm{OP}_{10}$ and $\mathrm{OP}_{5} \mathrm{~A}$ groups as compared with control one. Feeding OP and A. awamori showed a remarkable decrease $(P<0.05)$ effect in yolk total lipids and yolk cholesterol during the third experimental period and the overall one (Table 5). These results indicate that prolongation of the feeding with OP and/or A. awamori could enhance the egg quality. Present results are in agreement with the reports of Zarei et al. (2011) and Al-Harthi and Attia (2015) who stated that dietary inclusion of OP with levels 10 and $20 \%$ into laying diets had an increment effect on yolk index, yolk:albumin ratio and HU score. The effect of feeding $A$. awamori was demonstrated by Saleh et al. (2017) who showed that egg quality parameters were not significantly altered in groups receiving different levels of Aspergillus or other probiotic microorganisms.

Tothe best ofourknowledge, studiesinvestigating the effect of feeding OP and $A$. awamori on egg yolk total lipids and cholesterol are very limited. OP and A. awamori showed noteworthy decrement effect on yolk total lipids and yolk cholesterol during the third experimental period (16-20 week of age) and the overall one (8-20 week of age) (Table 5). Little 
Table 3. Effect of different diets supplementation (olive pulp with or without Aspergillus awamori) on performance of laying quails from 8 to 20 week of age

\begin{tabular}{|c|c|c|c|c|c|c|c|c|}
\hline \multirow{2}{*}{ Indices } & \multicolumn{6}{|c|}{ Treatment group $^{1}$} & \multirow{2}{*}{ SEM $^{2}$} & \multirow{2}{*}{$P$-value } \\
\hline & $\mathrm{C}$ & A & $\mathrm{OP}_{5}$ & $\mathrm{OP}_{5} \mathrm{~A}$ & $\mathrm{OP}_{10}$ & $\mathrm{OP}_{10} \mathrm{~A}$ & & \\
\hline \multicolumn{9}{|l|}{ Body weight, g } \\
\hline initial & 198 & 197 & 199 & 198 & 196 & 205 & 1.676 & 0.700 \\
\hline final & 280 & 271 & 286 & 278 & 274 & 285 & 3.510 & 0.491 \\
\hline \multicolumn{9}{|c|}{ Feed consumption, g/bird/day } \\
\hline weeks 8-12 & 20.50 & 20.20 & 22.77 & 22.80 & 21.37 & 20.30 & 0.364 & 0.068 \\
\hline weeks 12-16 & 24.30 & 24.03 & 27.37 & 25.00 & 25.57 & 24.67 & 0.419 & 0.218 \\
\hline weeks $16-20$ & 26.17 & 26.43 & 30.03 & 28.27 & 28.40 & 27.27 & 0.457 & 0.111 \\
\hline overall & 23.67 & 23.56 & 26.72 & 25.36 & 25.11 & 24.08 & 0.395 & 0.132 \\
\hline \multicolumn{9}{|c|}{ Feed conversion ratio, g feed/g egg } \\
\hline weeks 8-12 & 2.48 & 2.47 & 2.18 & 2.55 & 2.31 & 2.49 & 0.056 & 0.399 \\
\hline weeks 12-16 & 2.63 & 2.62 & 2.34 & 2.48 & 2.44 & 2.65 & 0.049 & 0.377 \\
\hline weeks $16-20$ & 2.73 & 2.81 & 2.48 & 2.70 & 2.62 & 2.85 & 0.056 & 0.487 \\
\hline overall & 2.62 & 2.64 & 2.34 & 2.58 & 2.46 & 2.67 & 0.052 & 0.456 \\
\hline \multicolumn{9}{|l|}{ Egg weight, g } \\
\hline weeks 8-12 & 10.69 & 10.53 & 13.34 & 11.56 & 11.89 & 10.77 & 0.367 & 0.213 \\
\hline weeks 12-16 & 12.22 & 12.75 & 12.72 & 14.30 & 12.94 & 13.46 & 0.260 & 0.267 \\
\hline weeks 16-20 & $11.98^{b}$ & $12.17^{\mathrm{ab}}$ & $12.29^{\mathrm{ab}}$ & $14.04^{\mathrm{a}}$ & $14.10^{\mathrm{a}}$ & $13.78^{\mathrm{ab}}$ & 0.300 & 0.050 \\
\hline overall & $11.63^{b}$ & $11.82^{b}$ & $12.78^{\mathrm{ab}}$ & $13.30^{a}$ & $12.98^{\mathrm{ab}}$ & $12.67^{\mathrm{ab}}$ & 0.183 & 0.018 \\
\hline \multicolumn{9}{|l|}{ Egg number } \\
\hline weeks 8-12 & 21.03 & 21.36 & 21.56 & 21.57 & 21.50 & 21.21 & 0.075 & 0.226 \\
\hline weeks 12-16 & $24.74^{c}$ & $25.15^{b c}$ & $25.37^{\mathrm{ab}}$ & $25.55^{\mathrm{ab}}$ & $25.70^{a}$ & $25.44^{\mathrm{ab}}$ & 0.085 & 0.001 \\
\hline weeks 16-20 & $25.72^{d}$ & $25.90^{\mathrm{cd}}$ & $26.31^{\mathrm{ab}}$ & $26.54^{a}$ & $26.57^{\mathrm{a}}$ & $26.14^{b c}$ & 0.080 & $<0.001$ \\
\hline overall & $23.83^{c}$ & $24.14^{\mathrm{bc}}$ & $24.41^{\mathrm{ab}}$ & $24.55^{\mathrm{a}}$ & $24.59^{\mathrm{a}}$ & $24.26^{\mathrm{ab}}$ & 0.070 & $<0.001$ \\
\hline \multicolumn{9}{|c|}{ Egg mass, g/hen/day } \\
\hline weeks 8-12 & 8.27 & 8.19 & 10.47 & 9.09 & 9.31 & 8.27 & 0.296 & 0.165 \\
\hline weeks 12-16 & 9.24 & 9.18 & 11.73 & 10.23 & 10.58 & 9.42 & 0.332 & 0.174 \\
\hline weeks 16-20 & 9.59 & 9.45 & 12.14 & 10.62 & 10.93 & 9.67 & 0.350 & 0.174 \\
\hline overall & 9.03 & 8.94 & 11.45 & 9.98 & 10.27 & 9.12 & 0.326 & 0.171 \\
\hline
\end{tabular}

1 treatment groups: $\mathrm{C}$ - corn-based diet, $\mathrm{A}-1 \mathrm{~g} / \mathrm{kg}$ A. awamori, $\mathrm{OP}_{5}-5 \%$ olive pulp, $\mathrm{OP}_{5} \mathrm{~A}-5 \%$ olive pulp $+1 \mathrm{~g} / \mathrm{kg}$ A. awamori, $\mathrm{OP}_{10}-10 \%$ olive pulp, $\mathrm{OP}_{10} \mathrm{~A}-10 \%$ olive pulp $+1 \mathrm{~g} / \mathrm{kg} \mathrm{A}$. awamori; ${ }^{2} \mathrm{SEM}$ - standard error of means; ${ }^{\mathrm{a}-\mathrm{d}}$ - means with different superscripts are significantly different

is known about the mechanism by which probiotics reduce the cholesterol content in eggs (Tang et al., 2015). However, the proposed mechanism by which A. awamori decrease yolk cholesterol content might be attributed to the fermentation occurred by $A$. awamori, which produces short-chain fatty acids that suppress hepatic cholesterol synthesis (Hara et al., 1999) and stimulate bile acid synthesis (Imaizumi et al., 1992). Moreover, A. awamori, as a probiotic, has the ability to alter the pathways of cholesteryl-esters and lipoprotein transporters (Liong et al., 2007), which might reduce the availability of cholesterol for deposition into egg yolks (Tang et al., 2015). Whereas, yolk cholesterol-lowering effect of OP may be due to its high contents of unsaturated fatty acids, especially n-3, n-6 and n-9, which might affect the quality of yolk-lipids contents (Hashish and Abd El-Samee, 2005). The authors reported decrease in egg yolk concentrations of total lipids, TC, TG, LDL-cholesterol and phospholipids in group fed olive cake compared to the control group. Moreover, Saleh et al. (2017) found a significant decrease in the yolk cholesterol in groups fed $A$. awamori. Other researchers observed also the beneficial effects of probiotic on egg quality such as lower cholesterol content (Mikulski et al., 2012; Tang et al., 2015).

Nowadays, the demand for low-cholesterol or low-saturated fat eggs has been increased because of the growing passion of health-conscious customers for healthier foods. Therefore, it would be convenient financially for egg producers to be able to produce and market low-cholesterol eggs. Egg producers have accomplished the decrease in egg cholesterol and fat by choosing eggs from hens of specific ages that are nourished on special diets, and these eggs are tagged as 'lowered fat and lowered 
Table 4. Effect of different diets supplementation (olive pulp with or without Aspergillus awamori) on egg quality criteria of laying quails from 8-12, 12-16 and 16-20 week of age

\begin{tabular}{|c|c|c|c|c|c|c|c|c|}
\hline \multirow{2}{*}{ Indices } & \multicolumn{6}{|c|}{ Treatment group ${ }^{1}$} & \multirow{2}{*}{ SEM $^{2}$} & \multirow{2}{*}{$P$-value } \\
\hline & $\mathrm{C}$ & $A$ & $\mathrm{OP}_{5}$ & $\mathrm{OP}_{5} \mathrm{~A}$ & $\mathrm{OP}_{10}$ & $\mathrm{OP}_{10} \mathrm{~A}$ & & \\
\hline \multicolumn{9}{|l|}{ Albumen, $\%$} \\
\hline weeks $8-12$ & 58.60 & 58.74 & 58.84 & 58.40 & 57.01 & 58.62 & 0.375 & 0.797 \\
\hline weeks $12-16$ & 56.80 & 58.86 & 58.79 & 57.59 & 55.85 & 57.64 & 0.376 & 0.139 \\
\hline weeks $16-20$ & 58.36 & 60.08 & 59.32 & 57.57 & 57.23 & 57.84 & 0.373 & 0.192 \\
\hline \multicolumn{9}{|l|}{ Yolk, \% } \\
\hline weeks $8-12$ & 29.35 & 29.95 & 28.69 & 29.04 & 29.41 & 29.96 & 0.323 & 0.891 \\
\hline weeks $12-16$ & 30.91 & 29.65 & 29.68 & 30.98 & 30.86 & 30.27 & 0.245 & 0.121 \\
\hline weeks $16-20$ & $29.59^{b}$ & $29.78^{b}$ & $29.70^{\mathrm{b}}$ & $31.19^{a}$ & $31.45^{a}$ & $31.01^{\mathrm{a}}$ & 0.263 & 0.039 \\
\hline \multicolumn{9}{|l|}{ Shell, \% } \\
\hline weeks $8-12$ & 12.05 & 11.31 & 12.47 & 12.57 & 13.58 & 11.42 & 0.353 & 0.501 \\
\hline weeks $12-16$ & 12.29 & 11.49 & 11.53 & 11.43 & 13.29 & 12.09 & 0.274 & 0.365 \\
\hline weeks $16-20$ & 11.15 & 10.14 & 10.99 & 11.24 & 11.31 & 12.05 & 0.293 & 0.662 \\
\hline \multicolumn{9}{|l|}{ Egg shape index } \\
\hline weeks 8-12 & 80.70 & 79.26 & 80.34 & 81.49 & 76.82 & 83.21 & 0.809 & 0.333 \\
\hline weeks $12-16$ & 76.70 & 78.31 & 79.84 & 78.72 & 80.77 & 82.90 & 0.795 & 0.310 \\
\hline weeks $16-20$ & $76.57^{b}$ & $79.16^{a}$ & $80.72^{\mathrm{a}}$ & $79.98^{\mathrm{a}}$ & $76.91^{b}$ & $80.49^{a}$ & 0.570 & 0.048 \\
\hline \multicolumn{9}{|l|}{ Yolk index } \\
\hline weeks $8-12$ & 45.86 & 41.98 & 40.56 & 40.50 & 46.64 & 45.02 & 1.031 & 0.334 \\
\hline weeks $12-16$ & 47.99 & 45.11 & 44.05 & 39.56 & 41.27 & 44.61 & 1.589 & 0.771 \\
\hline weeks $16-20$ & 37.55 & 38.05 & 40.05 & 41.32 & 40.36 & 39.06 & 0.723 & 0.714 \\
\hline \multicolumn{9}{|c|}{ Shell thickness, $\mathrm{mm}$} \\
\hline weeks $8-12$ & 0.376 & 0.305 & 0.330 & 0.309 & 0.383 & 0.324 & 0.015 & 0.586 \\
\hline weeks $12-16$ & 0.410 & 0.339 & 0.350 & 0.399 & 0.398 & 0.335 & 0.013 & 0.404 \\
\hline weeks $16-20$ & 0.323 & 0.307 & 0.371 & 0.333 & 0.342 & 0.321 & 0.010 & 0.558 \\
\hline \multicolumn{9}{|c|}{ Yolk: albumen ratio } \\
\hline weeks $8-12$ & 0.503 & 0.510 & 0.488 & 0.498 & 0.516 & 0.511 & 0.008 & 0.944 \\
\hline weeks $12-16$ & 0.544 & 0.505 & 0.505 & 0.538 & 0.553 & 0.526 & 0.007 & 0.112 \\
\hline weeks $16-20$ & $0.507^{b}$ & $0.497^{\mathrm{b}}$ & $0.501^{b}$ & $0.542^{\mathrm{a}}$ & $0.550^{\mathrm{a}}$ & $0.536^{a}$ & 0.007 & 0.032 \\
\hline \multicolumn{9}{|l|}{ Haugh unit score } \\
\hline weeks $8-12$ & 91.98 & 92.88 & 88.21 & 87.94 & 88.88 & 91.83 & 1.142 & 0.754 \\
\hline weeks $12-16$ & 88.61 & 88.82 & 90.26 & 89.42 & 92.29 & 90.54 & 0.773 & 0.818 \\
\hline weeks $16-20$ & $87.38^{b}$ & $84.98^{b}$ & $86.54^{\mathrm{b}}$ & $93.00^{\mathrm{a}}$ & $93.63^{a}$ & $89.47^{\mathrm{ab}}$ & 1.064 & 0.046 \\
\hline
\end{tabular}

${ }^{1}$ treatment groups: $\mathrm{C}$ - corn-based diet, $\mathrm{A}-1 \mathrm{~g} / \mathrm{kg}$ A. awamori, $\mathrm{OP}_{5}-5 \%$ olive pulp, $\mathrm{OP}_{5} \mathrm{~A}-5 \%$ olive pulp $+1 \mathrm{~g} / \mathrm{kg} \mathrm{A}$. awamori, $\mathrm{OP}_{10}-10 \%$ olive pulp, $\mathrm{OP}_{10} \mathrm{~A}-10 \%$ olive pulp $+1 \mathrm{~g} / \mathrm{kg} \mathrm{A}$. awamori; ${ }^{2} \mathrm{SEM}$ - standard error of means; ${ }^{\text {ab }}$ - means with different superscripts are significantly different

Table 5. Effect of different diets supplementation (olive pulp with or without Aspergillus awamori) on yolk total lipids and total cholesterol content of laying quails from 8 to 20 week of age

\begin{tabular}{|c|c|c|c|c|c|c|c|c|}
\hline \multirow{2}{*}{ Indices } & \multicolumn{6}{|c|}{ Treatment group $^{1}$} & \multirow{2}{*}{ SEM $^{2}$} & \multirow{2}{*}{$P$-value } \\
\hline & $\mathrm{C}$ & A & $\mathrm{OP}_{5}$ & $\mathrm{OP}_{5} \mathrm{~A}$ & $\mathrm{OP}_{10}$ & $\mathrm{OP}_{10} \mathrm{~A}$ & & \\
\hline \multicolumn{9}{|c|}{ Yolk total lipids, mg/g yolk } \\
\hline weeks $8-12$ & 352.8 & 347.1 & 346.4 & 348.7 & 352.3 & 347.0 & 1.450 & 0.736 \\
\hline weeks 12-16 & $357.9^{a}$ & $316.0^{\text {cd }}$ & $329.6^{b}$ & $309.5^{\text {cd }}$ & $321.4^{b c}$ & $306.8^{d}$ & 4.268 & $<0.001$ \\
\hline weeks 16-20 & $352.3^{\mathrm{a}}$ & $274.9^{c}$ & $302.7^{b}$ & $260.3^{d}$ & $280.5^{c}$ & $256.6^{d}$ & 7.973 & $<0.001$ \\
\hline overall & $354.3^{\mathrm{a}}$ & $312.7^{\mathrm{cd}}$ & $326.2^{\mathrm{b}}$ & $306.2^{\mathrm{cd}}$ & $318.1^{\mathrm{bc}}$ & $303.5^{\mathrm{d}}$ & 4.247 & $<0.001$ \\
\hline \multicolumn{9}{|c|}{ Yolk total cholesterol, mg/gyolk } \\
\hline weeks 8-12 & 18.54 & 18.37 & 18.59 & 18.00 & 18.52 & 17.67 & 0.136 & 0.312 \\
\hline weeks 12-16 & 19.89 & 18.60 & 18.90 & 18.19 & 18.54 & 17.71 & 0.240 & 0.140 \\
\hline weeks $16-20$ & $19.62^{\mathrm{a}}$ & $17.21^{\mathrm{b}}$ & $17.57^{b}$ & $16.76^{b}$ & $16.93^{b}$ & $16.12^{b}$ & 0.297 & 0.001 \\
\hline overall & $19.35^{\mathrm{a}}$ & $18.06^{b}$ & $18.35^{\mathrm{ab}}$ & $17.65^{b}$ & $18.00^{b}$ & $17.17^{\mathrm{b}}$ & 0.189 & 0.003 \\
\hline
\end{tabular}

${ }^{1}$ treatment groups: $\mathrm{C}$ - corn-based diet, $\mathrm{A}-1 \mathrm{~g} / \mathrm{kg} \mathrm{A}$. awamori, $\mathrm{OP}_{5}-5 \%$ olive pulp, $\mathrm{OP}_{5} \mathrm{~A}-5 \%$ olive pulp $+1 \mathrm{~g} / \mathrm{kg} \mathrm{A}$. awamori, $\mathrm{OP}_{10}-10 \%$ olive pulp, $\mathrm{OP}_{10} \mathrm{~A}-10 \%$ olive pulp $+1 \mathrm{~g} / \mathrm{kg} \mathrm{A}$. awamori; ${ }^{2} \mathrm{SEM}$ - standard error of means; ${ }^{\mathrm{a}-\mathrm{d}}-{ }^{5}$ means with different superscripts are significantly different 
cholesterol' and marketed (Bradley and King, 2016). It has been declared that hen age can influence the cholesterol content of egg yolk (Zemková et al., 2007) and younger hens tend to lay eggs with elevated cholesterol level (Oloyo, 2003). The ability of OP and A. awamori to reduce the yolk total lipids and cholesterol levels at periods of 16-20 and 8-20 weeks of age in this study could be exploited by egg producers for lowering the yolk cholesterol in layers during the early laying period. Egg consumption has been reported to contribute to $32 \%$ of TC intake (Hu et al., 1999), subsequently; a diminishment in yolk cholesterol might be beneficial to consumers, particularly to hyper-responders to dietary fats.

\section{Serum biochemical parameters}

AST, ALT and ALP activities, total protein and albumin values were insignificantly affected by all treatment groups (Table 6). Nevertheless, TG, TC and LDL-cholesterol values were decreased $(P<0.01)$ in all treatment groups except group $\mathrm{OP}_{5}$ for $\mathrm{TG}$ and A group for TC, while the significant increase $(P<0.01)$ in $\mathrm{HDL}$ value was observed only in $\mathrm{OP}_{10} \mathrm{~A}$ group in comparison with the control one. Moreover, antioxidant status of laying Japanese quails fed OP and/or A. awamori was improved $(P<0.01)$; significant increase in serum GSH value and GSR activity, and decrease in TBARS content were noticed in groups fed OP with or without A. awamori. Earlier, previous researches had proved that some oil sources (e.g., fish, soybean and olive oil), especially that have high content of oleic acid, exert potential detrimental effects on animals by increasing susceptibility to lipid or protein peroxidation in liver mitochondria (Huertas et al., 1992; Ochoa-Herrera et al., 2001; Quiles et al., 2006; Dong et al., 2018). So, we measured the serum values of AST and ALT as biomarkers for liver health in order to ensure the absence of any side effects on the liver exerted from the tested supplemental doses. In line with our results, Zangeneh and Torki (2011) stated that dietary OP inclusion did not exert any significant effect on the blood parameters. Hashish and Abd El-Samee (2005) demonstrated that using 10 and $20 \%$ of olive cake had no significant effect on TG content but level of 5\% reduced plasma cholesterol concentration. While, Zarei et al. (2011) reported that the inclusion of OP in hens diet decreased blood level of TG but not affected levels of TC, HDL and LDL. The reason for the hypocholesterolemic effect of OP may be due to its high content of fibre, which increases dietary fibre which in turn may reduce blood fat levels but the mechanisms are not fully understood (Razdan and Pettersson, 1994). It has been proposed that the increased viscosity associated with soluble fibres may postpone the emptying of the gastrointestinal tract, decrease intestinal motility and fat absorption thereby reducing lipid absorption (Razdan and Pettersson, 1994).

Table 6. Effect of different diets supplementation (olive pulp with or without Aspergillus awamori) on blood components and oxidative status of laying quails at 20 week of age

\begin{tabular}{|c|c|c|c|c|c|c|c|c|}
\hline \multirow{2}{*}{ Blood components } & \multicolumn{6}{|c|}{ Treatment group ${ }^{1}$} & \multirow{2}{*}{ SEM $^{2}$} & \multirow{2}{*}{$P$-value } \\
\hline & $\mathrm{C}$ & A & $\mathrm{OP}_{5}$ & $\mathrm{OP}_{5} \mathrm{~A}$ & $\mathrm{OP}_{10}$ & $\mathrm{OP}_{10} \mathrm{~A}$ & & \\
\hline \multicolumn{9}{|l|}{ Protein fractions, g/dl } \\
\hline total protein & $3.028^{\mathrm{ab}}$ & $2.563^{b}$ & $3.191^{\mathrm{ab}}$ & $4.085^{a}$ & $4.004^{a}$ & $3.379^{a b}$ & 0.155 & 0.007 \\
\hline albumin & 1.810 & 1.760 & 1.789 & 2.430 & 2.098 & 1.675 & 0.092 & 0.131 \\
\hline \multicolumn{9}{|l|}{ Enzymes activity, U/l } \\
\hline AST & 119.2 & 117.2 & 115.8 & 116.6 & 109.9 & 108.8 & 2.023 & 0.664 \\
\hline ALT & 90.11 & 89.86 & 105.05 & 106.93 & 105.75 & 96.88 & 2.586 & 0.147 \\
\hline ALP & 229.7 & 222.9 & 195.2 & 212.9 & 221.9 & 229 & 4.741 & 0.296 \\
\hline \multicolumn{9}{|l|}{ Lipid profile, mg/dl } \\
\hline triglycerides & $2667^{a}$ & $1934^{\mathrm{bc}}$ & $2343^{a b}$ & $1905^{\mathrm{bc}}$ & $1719^{b c}$ & $1653^{c}$ & 106.2 & 0.002 \\
\hline total cholesterol & $275.9^{a}$ & $228.5^{\mathrm{ab}}$ & $239.2^{\mathrm{bc}}$ & $197.1^{\mathrm{bc}}$ & $201.9^{b c}$ & $187.7^{\circ}$ & 8.00 & $<0.001$ \\
\hline HDL-cholesterol & $27.8^{\mathrm{b}}$ & $38.65^{b}$ & $36.27^{b}$ & $39.38^{b}$ & $41.8^{b}$ & $56.6^{\mathrm{a}}$ & 2.536 & 0.001 \\
\hline LDL-cholesterol & $134^{\mathrm{a}}$ & $87.42^{b}$ & $83.9^{b}$ & $73.0^{\mathrm{b}}$ & $92.10^{b}$ & $67.02^{b}$ & 7.111 & 0.018 \\
\hline \multicolumn{9}{|l|}{ Oxidative status } \\
\hline $\mathrm{GSH}, \mathrm{ng} / \mathrm{ml}$ & $0.181^{b}$ & $0.220^{a}$ & $0.222^{\mathrm{a}}$ & $0.236^{a}$ & $0.233^{a}$ & $0.253^{a}$ & 0.007 & 0.001 \\
\hline $\mathrm{GSR}, \mathrm{mU} / \mathrm{ml}$ & $0.182^{b}$ & $0.203^{a b}$ & $0.216^{a}$ & $0.218^{a}$ & $0.230^{\mathrm{a}}$ & $0.239^{a}$ & 0.006 & 0.001 \\
\hline $\mathrm{MDA}, \mu \mathrm{mol}$ & $0.307^{a}$ & $0.161^{c}$ & $0.196^{b c}$ & $0.221^{b c}$ & $0.228^{b}$ & $0.211^{\mathrm{bc}}$ & 0.012 & $<0.001$ \\
\hline
\end{tabular}

${ }^{1}$ treatment groups: $\mathrm{C}$ - corn-based diet, $\mathrm{A}-1 \mathrm{~g} / \mathrm{kg}$ A. awamori, $\mathrm{OP}_{5}-5 \%$ olive pulp, $\mathrm{OP}_{5} \mathrm{~A}-5 \%$ olive pulp $+1 \mathrm{~g} / \mathrm{kg}$ A. awamori, $\mathrm{OP}_{10}-10 \%$ olive pulp, $\mathrm{OP}_{10} \mathrm{~A}-10 \%$ olive pulp $+1 \mathrm{~g} / \mathrm{kg}$ A. awamori; AST - aspartate aminotransferase, ALT - alanine aminotransferase, ALP - alkaline phosphatase, HDL - high-density lipoprotein, LDL - low-density lipoprotein, GSH - glutathione reduced, GSR - glutathione reductase, MDA - malondialdehyde, ${ }^{2}$ SEM - standard error of means; ${ }^{a-d}$ - means with different superscripts are significantly different 
A. awamori inclusion into laying diets showed hypocholesterolemic effect while serum AST and ALP were not influenced (Saleh et al., 2017). Comparable lipid-lowering effects were considered in chickens fed diet containing A. oryzae (Kim et al., 2003; Panda et al., 2006; Sallh and Al Hussary, 2009) and A. niger (Yoon et al., 2004; Al-Kassie et al., 2008). The postulated mechanisms by which A. awamori, as a probiotic, decreases serum cholesterol include the retardation of cholesterol synthesis via the inhibition of 3-hydroxyl-3-methylglutarylcoenzyme (HMG-CoA) reductase (Hajjaj et al., 2005), its ability to produce bile salt hydrolase enzyme (BSH) (EC 3.5.1.24) for bile salt deconjugation in the enterohepatic circulation (Klaver and Van der Meer, 1993), the assimilation of cholesterol by probiotics to incorporate dietary cholesterol into their cellular membrane (St-Onge et al., 2000), and the conversion of cholesterol by probiotics in the intestine into coprostanol, which is directly excreted with the feaces (Ooi and Liong, 2010).

To our knowledge, studies conducted to investigate the effect of dietary OP supplementation in antioxidant system of poultry are very limited. The amelioration effect of OP on quail antioxidant status may be due to its contents of polyphenols and unsaturated fatty acids what could be attributed to increasing lipoprotein synthesis in the liver which in turn boosted the antioxidant defence system of birds (Al-Harthi and Attia, 2015). As well as, Visioli et al. (1995) and Aldini et al. (2006) identified olive mill waste as a potential source for the recovery of antioxidant and anti-atherogenic (Léger et al., 2000) because its contents of triterpenes, pectins, oligosaccharides, oleuropeinand hydroxytyrosol (HT) (Bulotta et al., 2014) which are the main phenolic compounds. HT is one of major phenolic compounds present in olive fruit and it has been revealed to be the most interesting, because of its remarkable pharmacological and antioxidant activity (Fabiani et al., 2002; Visioli et al., 2004). The antioxidant properties of HT can be attributed to the presence of orthodihydroxy moiety, called orthodiphenol. Besides its capacity or ability for donating electrons, its high antioxidant efficiency is due to the scavenger capacity of free radicals during the process of oxidation. However, concerning the antioxidant effect of A. awamori, Saleh et al. $(2011 ; 2012)$ stated that the addition of $A$. awamori ( $0.05 \%$ or $0.1 \%$ ) or $A$. niger $(0.05 \%)$ to the diet decreased the TBARS value in the broiler breast muscle, indicating that the fungus has antioxidative properties. These results indicate that $A$. awamori produces antioxidative substances. In addition, feeding diets containing $A$. awamori increased the mRNA expressions of antioxidant enzymes (i.e., glutathione peroxidase, catalase and superoxide dismutase) (El-Deep et al., 2014).

\section{Conclusions}

The present study demonstrated for the first time the effect of the combination of olive pulp (OP) and Aspergillus awamori in laying Japanese quail diets. The supplementation of $\mathrm{OP}$ and/or A awamori caused a significant increases in egg weight, egg number, yolk content (\%), and egg shape index as well as improved antioxidant status, serum lipid profile and yolk cholesterol content without altering the rest of productive performance and egg quality parameters. Present study indicates that supplementation of OP and A. awamori alone or in a combination into laying Japanese quail diet could lead to the production of low-total lipids and low-cholesterol eggs, during the early laying periods, which will be beneficial for the consumer health.

\section{Acknowledgment}

This research was funded by the Egyptian Atomic Energy Authority under the promotion of research scheme.

\section{References}

Al-Harthi M.A., Attia Y.A., 2015. Effect of citric acid on the utilization of olive cake diets for laying hens. Ital. J. Anim. Sci. 14, 3966, https://doi.org/10.4081/ijas.2015.3966

Al-Kassie G.A.M., Al-Jumaa Y.M.F., Jameel Y.J., 2008. Effect of probiotic (Aspergillus niger) and prebiotic (Taraxacum officinale) on blood picture and biochemical properties of broiler chicks. Int. J. Poult. Sci. 7, 1182-1184, https://doi.org/10.3923/ ijps.2008.1182.1184

Aldini G., Piccoli A., Beretta G., Morazzoni P., Riva A., Marinello C., Maffei Facino R., 2006. Antioxidant activity of polyphenols from solid olive residues of c.v. Coratina. Fitoterapia 77 , 121-128, https://doi.org/10.1016/j.fitote.2005.11.010

AOAC International, 2000. Official Methods of Analysis of AOAC International. $17^{\text {th }}$ Edition. Gaithersburg, MD (USA)

AOAC International, 2003. Official Methods of Analysis of AOAC International. $17^{\text {th }}$ Edition. $2^{\text {nd }}$ Revision. Gaithersburg, MD (USA)

Bradley F.A., King A.J., 2016. Egg basics for the consumer: packaging, storage, and nutritional information. Publication 8154. University of California, Division of Agriculture and Natural Resources (UCANR). Oakland, CA (USA)

Bulotta S., Celano M., Lepore S.M., Montalcini T., Pujia A., Russo D., 2014. Beneficial effects of the olive oil phenolic components oleuropein and hydroxytyrosol: focus on protection against cardiovascular and metabolic diseases. J. Transl. Med. 12, 219, https://doi.org/10.1186/s12967-014-0219-9

Dong X.F., Liu S., Tong J.M., 2018. Comparative effect of dietary soybean oil, fish oil, and coconut oil on performance, egg quality and some blood parameters in laying hens. Poult. Sci. 97, 2460-2472, https://doi.org/10.3382/ps/pey094 
El-Deep M.H., ljiri D., Eid Y.Z., Yamanaka H., Ohtsuka A., 2014. Effects of dietary supplementation with Aspergillus awamori on growth performance and antioxidative status of broiler chickens exposed to high ambient temperature. J. Poult. Sci. 51, 281-288, https://doi.org/10.2141/jpsa.0130154

Fabiani R., De Bartolomeo A., Rosignoli P., Servili M., Montedoro G., Morozzi G., 2002. Cancer chemoprevention by hydroxytyrosol isolated from virgin olive oil through $\mathrm{G} 1$ cell cycle arrest and apoptosis. Eur. J. Cancer Prev. 11, 351-358, https://doi. org/10.1097/00008469-200208000-00006

Folch J., Lees M., Sloane Stanley G., 1957. A simple method for the isolation and purification of total lipids from animal tissues. J. Biol. Chem. 226, 497-509

Grobas S., Mateos G.G., Mendez J., 1999. Influence of dietary linoleic acid on production and weight of eggs and egg components in young brown hens. J. Appl. Poult. Res. 8, 177-184, https://doi. org/10.1093/japr/8.2.177

Grobas S., Méndez J., Lázaro R., de Blas C., Mateo G.G., 2001. Influence of source and percentage of fat added to diet on performance and fatty acid composition of egg yolks of two strains of laying hens. Poult. Sci. 80, 1171-1179, https://doi.org/10.1093/ ps/80.8.1171

Güçlü B.K., Uyanık F., Işcan K.M., 2008. Effects of dietary oil sources on egg quality, fatty acid composition of eggs and blood lipids in laying quail. S. Afr. J. Anim. Sci. 38, 91-100

Hajjaj H., Duboc P., Fay L.B., Zbinden I., Macé K., Niederberger P., 2005. Aspergillus oryzae produces compounds inhibiting cholesterol biosynthesis downstream of dihydrolanosterol. FEMS Microbiol. Lett. 242, 155-159, https://doi.org/10.1016/j. femsle.2004.11.001

Hara H., Haga S., Aoyama Y., Kiriyama S., 1999. Short-chain fatty acids suppress cholesterol synthesis in rat liver and intestine. J. Nutr. 129, 942-948, https://doi.org/10.1093/jn/129.5.942

Hashish S.M., Abd El-Samee L.D., 2005. Effects of feeding olive cake and barley radicle as fiber sources on lipids, cholesterol and fatty acids in hen eggs.In: Proceedings of the World Poultry Science Association, $15^{\text {th }}$ European Symposium on Poultry Nutrition. Balatonfüred (Hungary), pp. 628-630

Hu F.B., Stampfer M.J., Rimm E.B. et al., 1999. A prospective study of egg consumption and risk of cardiovascular disease in men and women. JAMA 281, 1387-1394, https://doi.org/10.1001/ jama.281.15.1387

Huertas J.R., Battino M., Barzanti V., Maranesi M., Parenti-Castelli G., Littarru G., Turchetto E., Mataix F.J., Lenaz G., 1992. Mitochondrial and microsomal cholesterol mobilization after oxidative stress induced by adriamycin in rats fed with dietary olive and corn oil. Life Sci. 50, 2111-2118, https://doi. org/10.1016/0024-3205(92)90577-C

Imaizumi K., Hirata K., Yasni S., Sugano M., 1992. Propionate enhances synthesis and secretion of bile acids in primary cultured rat hepatocytes via succinyl CoA. Biosci. Biotechnol. biochem. 56, 1894-1896, https://doi.org/10.1271/bbb.56.1894

Kim S.H., Park S.Y., Yu D.J., Lee S.J., Ryu K.S., Lee D.G., 2003. Effects of feeding Aspergillus oryzae ferments on performance, intestinal microflora, blood serum components and environmental factors in broiler (in Korean). Korean J. Poult. Sci. 30, 151-159

Klaver F.A., van der Meer R., 1993. The assumed assimilation of cholesterol by Lactobacilli and Bifidobacterium bifidum is due to their bile salt-deconjugating activity. Appl. Environ. Microbiol. 59, 1120-1124

Léger C.L., Kadiri-Hassani N., Descomps B., 2000. Decreased superoxide anion production in cultured human promonocyte cells (THP-1) due to polyphenol mixtures from olive oil processing wastewaters. J. Agric. Food Chem. 48, 5061-5067, https://doi. org/10.1021/ff991349c
Liong M.-T., Dunshea F.R., Shah N.P., 2007. Effects of a synbiotic containing Lactobacillus acidophilus ATCC 4962 on plasma lipid profiles and morphology of erythrocytes in hypercholesterolaemic pigs on high-and low-fat diets. Br. J. Nutr. 98, 736-744, https://doi.org/10.1017/s0007114507747803

March B.E., MacMillan C., 1990. Linoleic acid as a mediator of egg size. Poult. Sci. 69, 634-639, https://doi.org/10.3382/ps.0690634

Mikulski D., Jankowski J., Naczmanski J., Mikulska M., Demey V., 2012. Effects of dietary probiotic (Pediococcus acidilactici) supplementation on performance, nutrient digestibility, egg traits, egg yolk cholesterol, and fatty acid profile in laying hens. Poult. Sci. 91, 2691-2700, https://doi.org/10.3382/ps.2012-02370

NRC (National Research Council), 1994. Nutrient Requirements of Poultry. $9^{\text {th }}$ Revised Edition. The National Academy Press. Washington, DC (USA), https://doi.org/10.17226/2114

Ochoa-Herrera J.J., Huertas J.R., Quiles J.L., Mataix J., 2001. Dietary oils high in oleic acid, but with different non-glyceride contents, have different effects on lipid profiles and peroxidation in rabbit hepatic mitochondria. J. Nutr. Biochem. 12, 357-364, https:// doi.org/10.1016/S0955-2863(01)00150-4

Oloyo R., 2003. Effect of age on total lipid and cholesterol of hen eggs. Indian J. Anim. Sci. 73, 93-100

Ooi L.-G., Liong M.-T., 2010. Cholesterol-lowering effects of probiotics and prebiotics: a review of in vivo and in vitro findings. Int. J. Mol. Sci. 11, 2499-2522, https://doi.org/10.3390/ ijms11062499

Panda A.K., Rao S.V.R., Raju M.V., Sharma S.R., 2006. Dietary supplementation of Lactobacillus sporogenes on performance and serum biochemico-lipid profile of broiler chickens. J. Poult. Sci. 43, 235-240, https://doi.org/10.2141/jpsa.43.235

Quiles J.L., Ochoa J.J., Ramirez-Tortosa M.C., Huertas J.R., Mataix J., 2006. Age-related mitochondrial DNA deletion in rat liver depends on dietary fat unsaturation. J. Gerontol. A Biol. Sci. Med. Sci. 61, 107-114, https://doi.org/10.1093/gerona/61.2.107

Ramasamy K., Abdullah N., Jalaludin S., Wong M., Ho Y.W., 2009. Effects of Lactobacillus cultures on performance of laying hens, and total cholesterol, lipid and fatty acid composition of egg yolk. J. Sci. Food Agric. 89, 482-486, https://doi.org/10.1002/ jsfa.3477

Razdan A., Pettersson D., 1994. Effect of chitin and chitosan on nutrient digestibility and plasma lipid concentrations in broiler chickens. Br. J. Nutr. 72, 277-288, https://doi.org/10.1079/bjn19940029

Saleh A.A., Eid Y.Z., Ebeid T.A., Kamizono T., Ohtsuka A., Hayashi K., 2011. Effects of feeding Aspergillus awamori and Aspergillus niger on growth performance and meat quality in broiler chickens. J. Poult. Sci. 48, 201-206, https://doi.org/10.2141/ jpsa.011019

Saleh A.A., Eid Y.Z., Ebeid T.A., Ohtsuka A., Hioki K., Yamamoto M., Hayashi K., 2012. The modification of the muscle fatty acid profile by dietary supplementation with Aspergillus awamori in broiler chickens. Br. J. Nutr. 108, 1596-1602, https://doi. org/10.1017/s0007114511007069

Saleh A.A., Gálik B., Arpášová H., Capcarová M., Kalafová A., Šimko M., Juráček M., Rolinec M., Bíro D., Abudabos A., 2017. Synergistic effect of feeding Aspergillus awamori in laying hens. Ital. J. Anim. Sci. 16, 132-139, https://doi.org/10.1080/182805 1x.2016.1269300

Sallh N.R., Al Hussary N.A.J., 2009. Effect of probiotics supplementation on some biochemical parameters of broiler chickens (in Arabic). Iraqi J. Vet. Sci. 23, Suppl. 1, 239-249

Scott M.L., Nesheim M.C., Young R.J., 1976. Nutrition of the Chicken. $2^{\text {nd }}$ Edition. M.L. Scott \& Associates. Ithaca, NY (USA) 
St-Onge M.-P., Farnworth E.R., Jones P.J.H., 2000. Consumption of fermented and nonfermented dairy products: effects on cholesterol concentrations and metabolism. Am. J. Clin. Nutr. 71, 674-681, https://doi.org/10.1093/ajcn/71.3.674

Tang S.G.H., Sieo C.C., Kalavathy R., Saad W.Z., Yong S.T., Wong H.K., Ho Y.W., 2015. Chemical compositions of egg yolks and egg quality of laying hens fed prebiotic, probiotic, and synbiotic diets. J. Food Sci. 80, C1686-C1695, https:// doi.org/10.1111/1750-3841.12947

Visioli F., Grande S., Bogani P., Galli C., 2004. The role of antioxidants in the Mediterranean diets: focus on cancer. Eur. J. Cancer Prev. 13, 337-343, https://doi.org/10.1097/01. cej.0000137513.71845.f6

Visioli F., Vinceri F., Galli C., 1995. 'Waste waters' from olive oil production are rich in natural antioxidants. Experientia 51, 32-34

Washburn K.W., Nix D.F., 1974. A rapid technique for extraction of yolk cholesterol. Poult. Sci. 53, 1118-1122, https://doi. org/10.3382/ps. 0531118

Yoon C., Na C.S., Park J.H., Han S.K., Nam Y.M., Kwon J.T., 2004. Effect of feeding multiple probiotics on performance and fecal noxious gas emission in broiler chicks (in Korean). Korean J. Poult. Sci. 31, 229-235
Yörük M., Gül M., Hayirli A., Macit M., 2004. The effects of supplementation of humate and probiotic on egg production and quality parameters during the late laying period in hens. Poult. Sci. 83, 84-88, https://doi.org/10.1093/ps/83.1.84

Zangeneh S., Torki M., 2011. Effects of $\beta$-mannanase supplementing of olive pulp-included diet on performance of laying hens, egg quality characteristics, humoral and cellular immune response and blood parameters. Global Vet. 7, 391-398

Zarei M., Ehsani M., Torki M., 2011. Productive performance of laying hens fed wheat-based diets included olive pulp with or without a commercial enzyme product. Afr. J. Biotechnol. 10, 4303-4312

Zemková L'., Simeonovová J., Lichovníková M., Somerlíková K., 2007. The effects of housing systems and age of hens on the weight and cholesterol concentration of the egg. Czech J. Anim. Sci. 52, 110-115, https://doi.org/10.17221/2269-CJAS 